\title{
ASSOCIATION OF MICROSATELLITE GENETIC DIVERSITY WITH GROWTH RELATED TRAITS IN THE BASE POPULATION OF AFRICAN CATFISH, Clarias gariepinus, BREEDING PROGRAM
}

\author{
Imron", Bambang Iswanto, Narita Syawalia Ridzwan, Rommy Suprapto, and Huria Marnis \\ Research Institute for Fish Breeding
}

(Received 26 March 2015; Final revised 29 May 2015; Accepted 8 June 2015)

\begin{abstract}
Genetic diversity at molecular level has been assumed to correlate with fitness related traits. However, accumulating evidences showed that the nature of that correlation has been variable. This study was aimed to explore the nature and possible mechanisms underlying that correlation by focusing on growth related traits in African catfish, Clarias gariepinus using microsatellite molecular markers. Fifty individual African catfish of 110 days-old were sampled and subjected to both morphological and molecular analyses. The standard length, total length and body weight as well as allelic scores of six microsatellite loci were measured on each individual. Indices of microsatellite diversity, namely individual multilocus heterozygosity (MLH) and mean microsatellite allelic distance (mean d2) for individual level, and mean observed heterozygosity $(\mathrm{Ho})$ and single-locus heterozygosity $(\mathrm{ho})$ for group level, were correlated to those traits using Pearson correlation coefficient $(r)$. The Hardy-Weinberg and linkage disequilibrium were carried out to explore the possible mechanisms underlying correlation. The results showed that at individual level the MLH and mean d2 were weakly correlated with standard length, $(r=0.25, p<0.05)$ and $(r=0.24, p<0.05)$, respectively. At group level, $H o$ was correlated with both standard and total length $(r=0.99, p<0.05)$ while ho identified two loci, $\mathrm{CgaO3}$ and $\mathrm{Cga06}$ significantly contributed to the correlation. Combining all relevant information, present study identified associative overdominance, both local effect and general effect hypotheses might responsible for the observed correlations.
\end{abstract}

KEYWORDS: microsatellite genetic diversity, multilocus heterozygosity, microsatellite allelic distance, observed heterozygosity, African catfish, Clarias gariepinus

\section{INTRODUCTION}

Genetic diversity detected at molecular level is widely assumed to correlate with phenotypic performance. This idea, commonly called as genetic diversity-fitness correlation (GDFC) (Da Silva et al., 2006), has long been argumentative (Reed \& Frankham, 2001) as accumulating empirical evidences have not always been consistent. Although most studies favour for the positive correlation (reviewed by Reed \& Frankham, 2003), other studies (e.g. Del Rio-Portilla \& Beaumont, 2000) and meta-analysis studies (Chapman et al., 2009; Heath et al., 2002) found a weak or non significant relationship. This variation seems to associate with various aspects such as genetic background of populations (Del Rio-Portilla \& Beaumont, 2000; Saavedra \& Guerra, 1996), life stages (Pierce \&

\# Corresponding: Research Institute for Fish Breeding Jl. Raya 2 Sukamandi, Subang 41263, West Java, Indonesia Tel.: + (0260) 520500

E-mail: imronnawawi@kkp.go.id
Mitton, 1982), traits being investigated (Heath et al., 2002), and molecular marker as well as diversity indices in use.

With respect to genetic markers, allozyme have dominated the study of GDFC. In reviewing this subject through meta analysis, Reed \& Frankham (2001) reported that over 70 percent studies on GDFC, have been done using allozyme markers. In recent years however, with the advance in molecular tools, particularly the polymerase chain reaction (PCR), the trend has been changing toward the use of microsatellite markers. These markers have advantages over allozymes as they are highly polymorphic, codominant, and selectively neutral, making it marker of choice for many genetic studies, including the studies of GDFC (Wright \& Bentzen, 1994).

Several measures of genetic diversity indices generated by microsatellite marker exist, some of which are heterozygosity $(\mathrm{H})$, and microsatellite allelic distance (d2) (Primmer \& Tiira, 2009). Heterozygosity 
can be analysed in two levels, namely group and individual levels. At group level, heterozygosity is defined as the proportion of heterozygote at all loci divided by all loci sampled (Frankham et al., 2002). At individual level, heterozygosity refers to the number of heterozygous allele within each individual. Heterozygosity at this level has commonly been called as individual heterozygosity (Appleyard et al., 2001; Mitton \& Pierce, 1980), or multilocus heterozygosity (MLH) (Chapman et al., 2009; Diehl \& Biesiot, 1994; Kittiwattanawong, 2001; Rolan-Alvarez et al., 1995; Slate et al., 2004). For the purpose of consistency we use this latter term throughout this paper. Another index of microsatellite genetic diversity is squared allelic distance $(\mathrm{d} 2)$. It represents the square of the difference in repeat units between the two alleles at a locus, and it assumes a stepwise mutation model. The latter measure was recently introduced (Coulson et al., 1998) and has been considered as a good indicator for capturing fitness effect of both ends of inbreeding-outbreeding spectrums (Hansson, 2010). Its use in the study of genotype-fitness correlation has been documented, for instance in chinook salmon, Oncorhynchus tshawytscha (Heath et al., 2002) and harp seals, Phoca groenlandica, (Kretzmann et al., 2006).

There have been at least three prevailing theoretical explanations for the GDFC. The first is direct overdominance hypothesis, where the scored loci might have a direct effect on individual fitness (Zouros et al., 1980). The second is associative over dominance in which linkage disequilibrium might result in association between marker loci and fitness loci (David et al., 1997). The latter hypothesis can be split further into local effect and general effect hypotheses (Liu et al., 2006). While the former occurs when fitness loci rest in the local surrounding chromosomal region, the latter occurs when heterozygosity at the markers might reflect variation in inbreeding coefficient and might associate with fitness as result of homozygosity at genome-wide distributed loci (Hansson \& Westerberg, 2002).

African catfish, Clarias gariepinus have been one of the highly popular food fish and has contributed significantly to the program of food security in Indonesia. Breeding program aiming at improving growth rate of this species has been started in 2011 at the Research Institute for Fish Breeding (RIFB) and a base population consisting of reciprocal crossing of four strains was established.

This study was designed to address a general question on the GDFC. Specifically, it was intended to explore several specific questions, namely: 1) whether correlation between genetic diversity and growth exist in captive population of African catfish, 2) the pattern and magnitude of genetic diversity-fitness correlation, 3) if the correlation exists, which parameter of genetic diversity indices could serve best as surrogate for fitness trait. Finally, it was also intended to explore which hypothesis, among the three, that may best explain the GDFC in captive population of African catfish. Those three questions were explored within the base population of African catfish breeding program using microsatellite molecular markers.

\section{MATERIALS AND METHODS}

\section{Sample}

Sample was a base population of African catfish breeding program at Research Institute for Fish Breeding (RIFB). It was a composite population made up of reciprocal mating among four geographic populations that were already distributed and widely used by catfish farmers. These founding populations were Sangkuriang, Dumbo, Paiton, and Egypt strains. Except the last one, the history and genetic attributes of the other three strains, as revealed by microsatellite markers, have been described by Imron et al. (2011). Fifty individual were randomly sampled at harvest (110 days old) and were used for growth-related trait measurement and microsatellite genotyping.

\section{Growth-Related Traits Measurement}

Growth-related traits assessed were standard length, total length and body weight. Standard length was measured to the nearest $1 \mathrm{~mm}$ using a plastic ruler, while body weight scaled to the nearest $0.2 \mathrm{~g}$ using Kern electric balance. Following these phenotypic measurement, 20-50 mg muscle tissue was taken from each individual sample for microsatellite analysis.

\section{Microsatellite Genotyping}

Microsatellite analysis was performed using six polymorphic loci (Galbusera et al., 1996) the description of which are described in Table 1. Genomic DNA was extracted from caudal fin of each the individual of African catfish. All extractions were performed by following the manufacturer's instructions (Gentra puregene, Qiagen). The protocol consists of series of steps including cell lysis, protein precipitation, DNA precipitation, washing and DNA hydration. Cell lysis was performed by weighing of approximately $10 \mathrm{mg}$ of tissue sample and mincing it with a surgical blade into small pieces. The tissue was lysed by adding 300 $\mu \mathrm{L}$ of cell lysis solution into a $1.5 \mathrm{~mL}$ microcentrifuge tube, $1.5 \mu \mathrm{L}$ of puregene proteinase $\mathrm{K}$, followed by incubation in $55^{\circ} \mathrm{C}$ for 3 hours and adding $1.5 \mu \mathrm{L}$ of RNase A solution followed by incubation in $37^{\circ} \mathrm{C}$ for $15 \mathrm{~min}$. The lysate was added $300 \mu \mathrm{L}$ with isopro- 
Table 1. Description of six microsatellite primers (Galbusera et al., 1996) used to amplify polymorphic microsatellite alleles in the base populations of Clarias gariepinus breeding program

\begin{tabular}{|c|c|c|c|c|}
\hline Locus & $\begin{array}{c}\text { Gene bank } \\
\text { accession number }\end{array}$ & Primer sequence (5’-3') & $\begin{array}{l}\text { Size range of } \\
\text { PCR product (bp) }\end{array}$ & $\operatorname{TM}\left({ }^{\circ} \mathrm{C}\right)$ \\
\hline $\operatorname{Cg} a 01$ & U30862 & $\begin{array}{l}\text { F: GGCTAAAAGAACCCTGTCTG } \\
\text { R: TACAGCGTCGATAAGCCAGG }\end{array}$ & $92-104$ & 59 \\
\hline Cga 02 & U30863 & $\begin{array}{l}\text { F: GCTAGTGTGAACGCAAGGC } \\
\text { R: ACCTCTGAGATAAAACACAGC }\end{array}$ & $102-110$ & 58 \\
\hline Cga 03 & U30864 & $\begin{array}{l}\text { F: CACTTCTTACATTTGTGCCC } \\
\text { R: AACCTGTATTGATTTCTTGCC }\end{array}$ & $142-168$ & 56 \\
\hline Cga 05 & U30866 & $\begin{array}{l}\text { F: TCCACATTAAGGACAACCACCG } \\
\text { R: TTTGCAGTTCACGACTGCCG }\end{array}$ & 204-212 & 60 \\
\hline Cga 06 & U30867 & $\begin{array}{l}\text { F: CAGCTCGTGTTTAATTTGGC } \\
\text { R: TTGTACGAGAACCGTGCCAGG }\end{array}$ & $134-142$ & 60 \\
\hline $\operatorname{Cg} a 09$ & U30871 & $\begin{array}{l}\text { F: CGTCCACTTCCCCTAGAGCG } \\
\text { R: CAGCTGCATTACCATACATGG }\end{array}$ & $180-196$ & 65 \\
\hline
\end{tabular}

$\mathrm{TM}=$ Annealing temperature

panol followed by vortexing for 50 seconds and then spinning at 16,000 $\mathrm{xg}$ for $1 \mathrm{~min}$. The supernatant was discarded and the pellet remains was taken care in the tube. The pellet DNA was then washed by adding $300 \mu \mathrm{L}$ of $70 \%$ ethanol, inverting several times and spinning at $16,000 \mathrm{xg}$ for $1 \mathrm{~min}$ by microcentrifuge. The supernatant was discarded carefully and adding $100 \mu \mathrm{L}$ DNA hydration solution and vortexing for 5 seconds at medium speed. Finally, the dissolved the DNA was incubated at $65^{\circ} \mathrm{C}$ for 1 hour. To check the success of genomic DNA extraction process, the sample was run on mini horizontal gel electrophoresis. The sample was loaded in to the $1 \%(\mathrm{w} / \mathrm{v})$ agarose gel, powered with 65 volt electricity and run for 70 minutes and viewed using gel documentation system ultraviolet transillumination. The purity and quantity of DNA was measured using a GeneQuant 1300.

\section{PCR Amplification and Genotyping and Allele Scoring}

A total of $2 \mathrm{~mL}$ (7200 ng) of extracted genomic DNA was amplified by using type-it microsatellite PCR (Qiagen). Amplification of polymorphic microsatellite locus was performed using thermal cycling system (mycycler, Biorad). The PCR process was done with the program: initial denaturing at $95^{\circ} \mathrm{C}$ for $5 \mathrm{~min}$; (denaturing at $95^{\circ} \mathrm{C}$ for 30 seconds; annealing at $50^{\circ} \mathrm{C}$ $62^{\circ} \mathrm{C}$ for 90 seconds depending on annealing temperature of each primer (Table 1); extension at $72^{\circ} \mathrm{C}$ for 30 seconds) for 30 cycles; and final extension $60^{\circ} \mathrm{C}$ for 30 minutes. PCR amplification results were checked by electrophoresis on $2 \%$ agarose gel that has given dyes GelRedTM (Biotium) and electrophoresis results were observed under UV light and photo- graphed using transluminator digital camera Canon EOS 1100D.

Polymorphism of microsatellite locus were screened using a fragment analysis tool QIAxcel (Qiagen) using DNA QIAxcel Screening kit (Qiagen), the size of the alleles was determined based on the relative size of the PCR products with reference to the size QX DNA marker 50-800 bp size marker (Qiagen). Electropherogram banding pattern data were analysed using QIAxcel ScreenGel software (Qiagen) for scoring alleles. The allelic data were then analysed further to generate various genetic parameters.

\section{Parameters and Data Analysis}

Four microsatellite genetic diversity indices were used to assess the association between genetic diversity and growth related traits. They were multilocus heterozygosity (MLH), mean microsatellite allelic distance (mean $\mathrm{d} 2$ ), and observed heterozygosity which was examined as mean observed heterozygosity $(\mathrm{Ho})$ and single locus observed heterozygosity (ho). The MLH and mean $\mathrm{d} 2$ are genetic diversity parameters treating individuals as study unit. In this way, each individual possesses observational value according to study design. In the current study, each individual had both record of growth related trait values and molecular data allowing correlation analysis to be done on individual basis. In contrast to this, observed heterozygosity ( $\mathrm{Ho}$ and $h o$ ) treat group as study unit. The following are mathematical expressions for obtaining those genetic diversity indices.

$\mathrm{MLH} i=\mathrm{N}$ heterozygous $(i) / \mathrm{N}$ genotyped $(i)$, that was the proportion of heterozygous microsatellite 
loci over all loci that have been successfully genotyped within each individual sample.

Mean microsatellite allelic distance (mean d2):

$$
\text { Mean } \mathrm{d} 2=\sum_{\mathrm{i}=1}^{\mathrm{n}}\left\{(i a-i b)^{2} / \mathrm{n}\right\}
$$

where:

$i a$ and $i b$ are the length of repeat unit of allele $a$ and $b$ at locus $i$ and $n$ is the number of typed loci (Hansson, 2010).

Mean observed heterozygosity $(\mathrm{Ho})=$ Total number of heterozygotes averaged over all loci / Sample size (Frankham et al., 2002)

Single-locus observed heterozygosity $(h o)=$ Total number of heterozygotes at single locus / Sample size (Frankham et al., 2002)

Microsatellite allelic data were analysed using FSTAT (Goudet, 2001) to obtain relevant genetic diversity parameters, particularly $\mathrm{Ho}$, ho and fixation index, Fis. The patterns and magnitude of GDFC were assessed using correlation analyses. To obtain an insight on the relationship between genetic diversity and growth related traits, correlation analyses were explored in two levels, namely individual and group. Individual-based correlation analysis was carried out by correlating the phenotypic and molecular data owned by each individual sample. Group-based correlation analysis was carried out through two steps; firstly, grouping individual sample into three size groups, followed by correlating the average values of both molecular marker and phenotypic traits within the respective groups.

Grouping of samples into three groups based on its size, namely small (S), medium (M), and large (L) was conducted based on the following quantitative criteria. The $S$ group were individuals with phenotypic value smaller than sample average minus one standard deviation (SD). Mathematically, it was expressed as $(\mathrm{Y}<\mathrm{X}$-1SD), where $\mathrm{Y}$ was observation value and $X$ was population average. The mediumsize group were those individual with phenotypic values falling within sample average plus/minus one $\mathrm{SD}((\mathrm{X}+1 \mathrm{SD})>\mathrm{Y}>(\mathrm{X}-1 \mathrm{SD}))$, and the L group were those with the value of phenotypic measurement larger than sample average plus $1 \mathrm{SD}(\mathrm{Y}>\mathrm{X}+1 \mathrm{SD})$. By applying these criteria, the distribution of 50 individual samples within the respective group is presented in Table 2. Statistical test contrasting the mean between groups (results not shown) found that they were significantly different $(p<0.05)$.

Direction or trend of the correlation, whether it is positive, negative or uncorrelated, was reflected in the sign of Pearson correlation coefficient $(r)$ which could be either positive, negative, or zero. In graphical illustration this was visualized in the slope of trend line. The magnitude of the correlation was expressed in the $r$-value, and its statistical significance was tested at $\alpha=0.05$. Null hypothesis (H0) of no correlation between microsatellite genetic diversity and growth related traits was tested against the alternative hypothesis (H1), in which correlations exist, either in positive or negative direction. All the analyses were performed in excel add-in analyse-it.

To address question on the possible mechanisms underlying correlation, if any, was explored in several ways: Hardy-Weinberg test, linkage disequilibrium, and single locus correlation analyses. Output of the analyses, namely the pattern of either heterozygote deficit or heterozygote excess, was then contrasted to prevailing hypotheses that were previously described, namely direct over dominance, local effect, and general effect hypotheses. Data analysis was done using genetic software Genepop (Raymond \& Rousset, 1995), Arlequin (Schneider et al., 2000), and FSTAT (Goudet, 2001).

\section{RESULTS}

\section{Correlation of Multilocus Heterozygosity with Growth-Related Traits}

The relative value of MLH calculated over six loci ranged from 0 to 0.83 . This mean that at one end

Table 2. Grouping of sample into small (S), medium (M), and large (L) groups on the bases of standard length. The $\mathrm{Y}, \mathrm{X}$ and $\mathrm{N}$ indicates observation value, sample average, and number of sample, respectively

\begin{tabular}{lccc}
\hline \multicolumn{1}{c}{ Group } & Criteria & $\begin{array}{c}\text { Range of standard } \\
\text { length }(\mathbf{c m})\end{array}$ & $\mathbf{N}$ \\
\hline Small & $\mathrm{Y}<\mathrm{X}-1 \mathrm{SD}$ & $19.1-21.2$ & 9 \\
Medium & $(\mathrm{X}+1 \mathrm{SD})>\mathrm{Y}>(\mathrm{X}-1 \mathrm{SD})$ & $21.9-23.4$ & 32 \\
Large & $\mathrm{Y}>\mathrm{X}+1 \mathrm{SD}$ & $28.5-33.0$ & 9 \\
\hline \multicolumn{2}{l}{ Total } & & 50 \\
\hline
\end{tabular}


several individuals had no loci with heterozygous allele $(\mathrm{MLH}=0)$ while at the other end, individuals had maximum 5 loci of heterozygous alleles (MLH $=0.83$ ). However, as can be seen in Figure 1, the number of individuals reside within both ends was scarce (less than five percent). Majority of the sample had 1-4 loci of heterozygous alleles. Figure 1 shows the direction and magnitude as well as statistical significance of correlation between this genetic diversity index and growth related traits. In general, there was positive correlation between MLH and growth related traits. This was shown by the slope of trend lines pointing toward up-right in plotting of MLH against standard length, total length and body weight (Figure 1). Despite positive, however, degree of correlations between MLH and growth related traits were relatively weak. The value of correlation coefficient $(r)$ for MLH-standard length, MLH-total length, and MLHbody weight were $0.25,0.22$ and 0.20 , respectively. Among these, only the correlation of MLH-standard length that was statistically significant $(p<0.05)$.

\section{Correlation of Mean d 2 to Growth Related Traits}

In line with MLH, the mean microsatellite allelic distance (mean $\mathrm{d} 2$ ) was positively correlated with growth related traits. The slope of trending line which toward up-right lend a support for this trend of cor- relation. However, the strength of correlation was also weak. They ranged from $0.19(p>0.05)$ for body weight to $0.24(p<0.05)$ for standard length (Figure 2 ). Under mean $\mathrm{d} 2$ perspective, more heterozygous individuals would have larger allele differences. This figure suggest that more homozygous individuals, namely those with less value of allele differences, performed poorer in all growth related traits than those with more distant allele difference.

\section{Correlation of Mean and Single Locus Hetero- zygosity with Growth Related Traits}

In contrast to those observed at individual level, association analyses conducted at group level, showed more significant correlation. Pearson coefficient correlation between mean observed heterozygosity and both standard and total lengths was 0,99 $(p<0.05)$, respectively, while that for body weight was 0,98 $(p>0.05)$ (Table 2$)$. This pattern of correlation means that there was a tight relationship when the samples were classified into small, medium and large groups, followed by correlating the mean phenotypic value of each group to the respective mean of the observed heterozygosity. The samples belonging to the smallsize group were found to have smallest mean heterozygosity. Likewise, group of medium and large size were found to have medium and largest observed
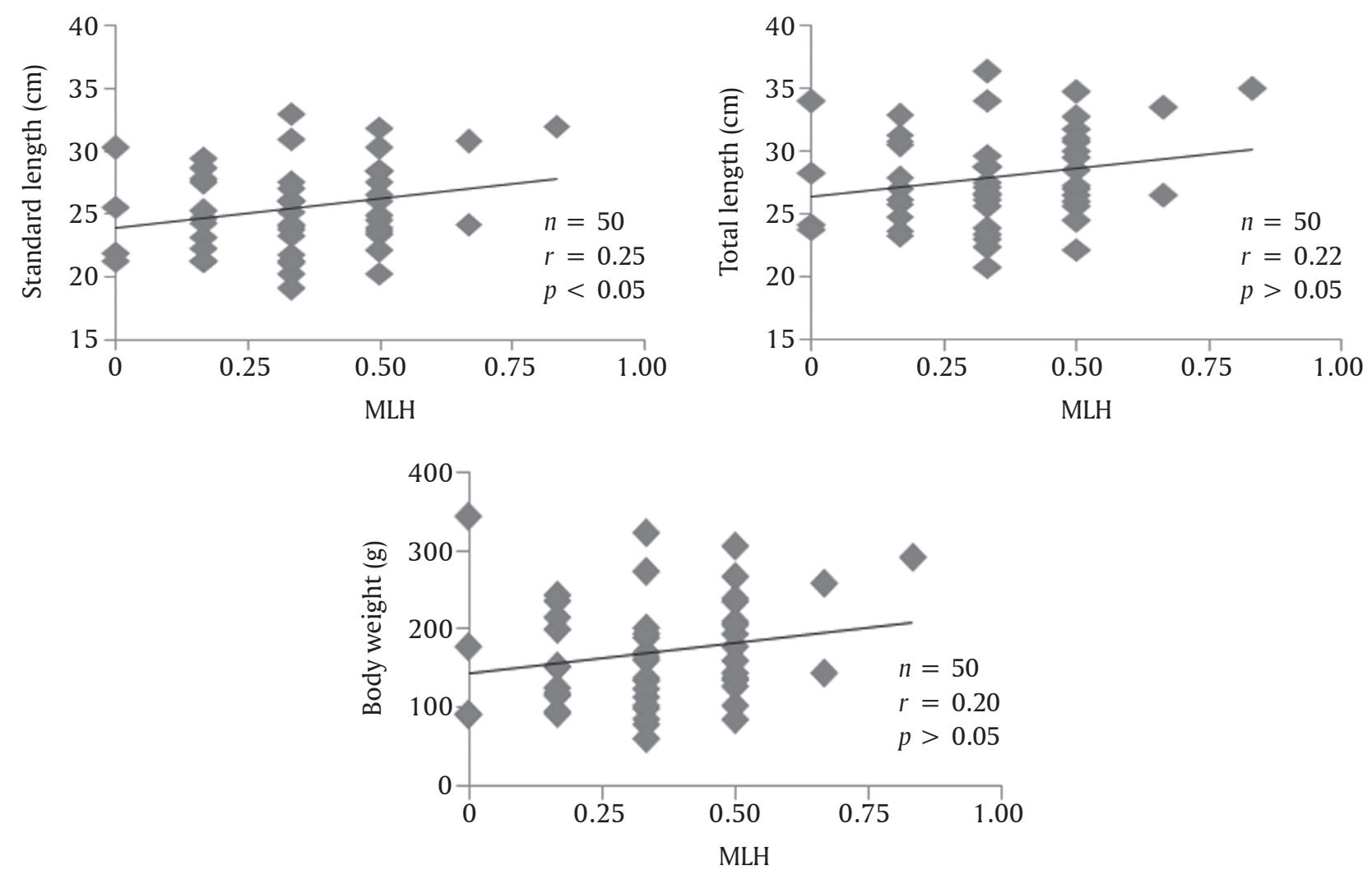

Figure 1. Association between multilocus heterozygosity (MLH) and growth-related traits, including standard length (A), total length (B) and body weight (C). The n, r, and p indicate number of sample, Pearson correlation coefficient, and statistical significance, respectively 

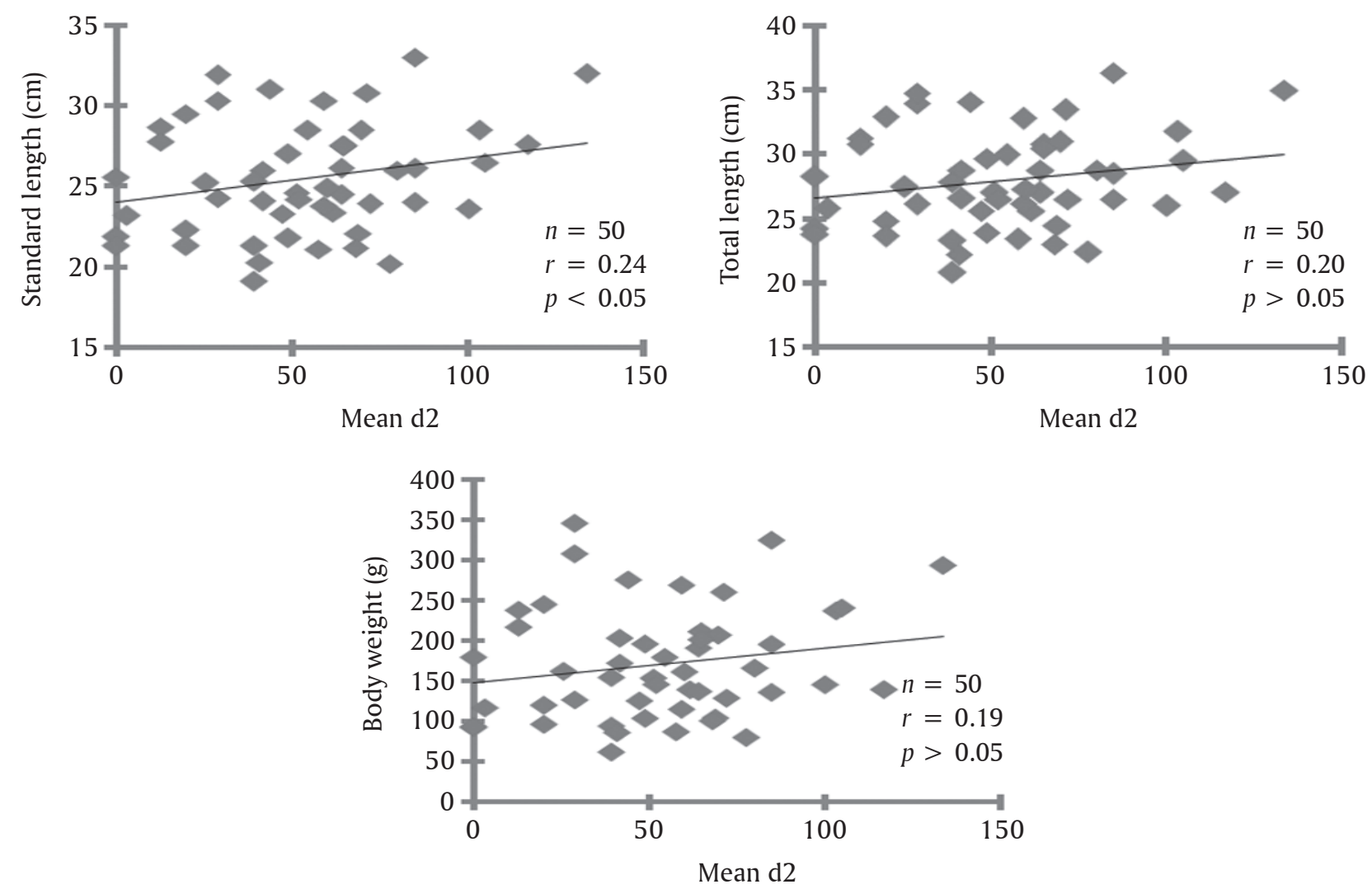

Figure 2. Association between mean $\mathrm{d} 2$ and growth related traits including standard length (A), total length (B) and body weight $(\mathrm{C})$. The $\mathrm{n}, \mathrm{r}$, and $\mathrm{p}$ indicate number of sample, Pearson correlation coefficient, and statistical significance, respectively

heterozygosity, respectively. The figure seems to show that mean observed heterozygosity appeared to be more sensitive in detecting genetic diversitygrowth related trait association.

While mean observed heterozygosity showed positive correlation, analysis on single locus showed that not all loci contributed in a similar way to the trend and degree of association. Out of six loci analysed, only two loci, namely $\mathrm{CgaO3}$ and $\mathrm{CgaO6}$ that were positively and significantly correlated $(p<0.05)$ with growth-related traits (Table 3). Trend and degree of correlation of the other loci, were positive, negative or uncorrelated, but they were all statistically not significant $(p>0.05)$ (Table 3$)$.

\section{Profile of Heterozygote Deficit and Linkage Disequilibrium}

Analyses of Hardy-Weinberg equilibrium presented in Table 3 showed that all loci significantly deviated from Hardy-Weinberg equilibrium. Specifically, all loci experienced heterozygote deficit and all were statistically significant $(p<0.05)$. This was observed in both single locus and combined loci analyses. Analysis of linkage disequilibrium (Table 5) showed that one pair loci ( $\mathrm{CgaO2}$ and $\mathrm{CgaO6})$ was in disequilibrium $(p<0.05)$ while other loci pairs were in equilibrium $(p>0.05)$.
This pattern was in line with the result of correlation between single-locus heterozygosity and growth related traits previously presented (Table 4).

\section{DISCUSSION}

Exploration on GDFC carried out in this study resulted in several interesting findings. They were: 1) the existence of the signal of correlation, 2) similarity in power between MLH and mean $\mathrm{d} 2$ as indicator in GDFC studies, 3) similarity in direction but not in magnitude between correlation profiles resulted from individual and those from group bases, 4) variation in magnitude of correlations among different measures of growth related traits, and 5) local and general effect hypotheses seemed to involve in the emergence of GDFC phenomena observed in this study. The following discussion describes those findings in detail.

\section{The Nature of GDFC in The Base Population of African Catfish Breeding Program}

The MLH has long been used as genetic diversity parameter in studies of GDFC. In contrast to this, mean $\mathrm{d} 2$ has been only recently introduced (Coulson et al., 1998). Present study found that both MLH and mean $\mathrm{d} 2$ gave similar results, namely weak, but posi- 
Table 3. Direction, magnitude, and statistical significance of correlation between both single locus (ho) and mean (Ho) observed heterozygosity and growth related traits in 110days old of African catfish base population. Sample size $=3$, degree of freedom $=1$

\begin{tabular}{|c|c|c|c|c|c|}
\hline \multirow{2}{*}{ Traits } & \multirow{2}{*}{ Locus } & \multicolumn{2}{|c|}{ Heterozygosity } & \multirow{2}{*}{ r-statistics } & \multirow{2}{*}{$\begin{array}{l}p \text {-value at } \\
\mathrm{H} 1 ; \mathrm{r} \neq 0\end{array}$} \\
\hline & & ho & Ho & & \\
\hline \multirow{7}{*}{ Standard length } & Cga01 & 0.78 & & -0.89 & 0.3002 \\
\hline & $\mathrm{Cga02}$ & 0.55 & & -0.07 & 0.9574 \\
\hline & Cga03 & 0.33 & & 1.00 & 0.0311 \\
\hline & Cga05 & 0 & & -0.85 & 0.3554 \\
\hline & Cga06 & 0.67 & & 1.00 & 0.0426 \\
\hline & Cga09 & 0.67 & & 0.92 & 0.2552 \\
\hline & All loci combined & & 0.311 & 0.99 & $<0.05$ \\
\hline \multirow{7}{*}{ Total length } & $\operatorname{Cg} a 01$ & 0.81 & & -0.89 & 0.3081 \\
\hline & $\operatorname{Cg} a 02$ & 0.53 & & -0.08 & 0.9495 \\
\hline & $\operatorname{Cga} 03$ & 0.21 & & 1.00 & 0.0390 \\
\hline & Cga 05 & 0.13 & & -0.85 & 0.3475 \\
\hline & Cga 06 & 0.50 & & 1.00 & 0.0505 \\
\hline & $\operatorname{Cga} 09$ & 0.56 & & 0.93 & 0.2474 \\
\hline & All loci combined & & 0.311 & 0.99 & $<0.05$ \\
\hline \multirow{7}{*}{ Body weight } & $\operatorname{Cg} a 01$ & 1.00 & & -0.85 & 0.3484 \\
\hline & $\operatorname{Cg} a 02$ & 0.44 & & -0.14 & 0.9093 \\
\hline & $\operatorname{Cg} a 03$ & 0.11 & & 0.99 & 0.0792 \\
\hline & $\operatorname{Cg} a 05$ & 0.11 & & -0.89 & 0.3092 \\
\hline & Cga 06 & 0.22 & & 0.99 & 0.0907 \\
\hline & $\operatorname{Cg} a 09$ & 0.56 & & 0.95 & 0.2071 \\
\hline & All loci combined & & 0.311 & 0.98 & $>0.05$ \\
\hline
\end{tabular}

tive and statistically significant correlations of both of them and standard length. This profile of correlation may reflect several indications. Firstly, within the population under study, the GDFC existed. This supports widely accepted thought and provides additional supporting evidence. Secondly, it lends some support that inbreeding may be involved in the emergence of the GDFC phenomena in this population. This argument is based on the proposal that mean $\mathrm{d} 2$ is considered as good indicator of individual inbreeding level (Hansson, 2010). Therefore, significant correlation between this parameter and growth related traits suggest that inbreeding could be involved as a causing agent underlying the GDFC within this study. Special discussion exploring the possible mechanisms underlying GDFC, described later in this paper, strengthening this proposition.

The lower magnitude of GDFC at individual level detected in this study could be explained because microsatellite loci are neutral marker giving no direct effect on the expression of fitness traits. Rather, it may work indirectly through association with loci affecting the fitness traits. Hence, degree of association between marker loci and fitness loci may determine the strength of association between marker loci and fitness traits. The weak association observed in this study might result from the situation in which marker loci were less associated with fitness loci. This was supported by the fact that based on single locus analysis, only two loci ( $\mathrm{CgaO3}$ and $\mathrm{CgaO6}$ ) which were significantly correlated with growth traits. The weak correlation at individual level detected in this study ( $r$ ranged from 0.19 to 0.25 ), albeit small, is within the range of previous studies. Bierne et al. (2000) for instance, found a weak but significant and positive correlation between microsatellite tri-locus heterozygosity and growth rate $(r=0.3, p=0.02)$. This relatively weak association was in contrast to those obtained at group level.

The relatively stronger association at group level suggest that overall heterozygosity, may have more important role in fitness trait. It also might indicate that population understudy had experienced some level of inbreeding depression. A comparable study 
Table 4. Profile of heterozygote deficit at six loci calculated on both single locus and combined bases. The ho, Ho, he and He refer to single-locus observed heterozygosity, mean observed heterozygosity, single-locus expected heterozygosity, and mean expected heterozygosity, respectively. Single and double asterisks next to p-value indicate statistical significance at $\alpha=0.05$ and $\alpha=0.01$, respectively

\begin{tabular}{|c|c|c|c|c|c|}
\hline \multirow[t]{2}{*}{ Locus } & \multicolumn{2}{|c|}{$\begin{array}{c}\text { Observed } \\
\text { heterozygosity }\end{array}$} & \multicolumn{2}{|c|}{$\begin{array}{c}\text { Expected } \\
\text { heterozygosity }\end{array}$} & \multirow[t]{2}{*}{$p$-value } \\
\hline & ho & Ho & he & He & \\
\hline Cga01 & 0.78 & & 0.913 & & $0.0426^{*}$ \\
\hline Cga02 & 0.55 & & 0.820 & & $0.0000^{*}$ \\
\hline Cga03 & 0.33 & & 0.735 & & 0.0000 \\
\hline Cga05 & 0 & & 0.795 & & $0.0000^{\text {䉺 }}$ \\
\hline Cga06 & 0.67 & & 0.833 & & $0.0000^{\circ}$ \\
\hline Cga09 & 0.67 & & 0.916 & & $0.0000^{*}$ \\
\hline All loci combined & & 0.311 & & 0.83878 & $0.0000^{\text {粬 }}$ \\
\hline
\end{tabular}

Table 5. Test of linkage disequilibrium over fifteen pairs loci. The Chi2, df, p-value indicate the value of chi square, degree of freedom and statistical significance, respectively

\begin{tabular}{cccc}
\hline Locus pair & Chi 2 & df & p-value \\
\hline Cga01 \& Cga02 & 4.051119 & 4 & 0.399132 \\
Cga01 \& Cga03 & 7.812147 & 4 & 0.098707 \\
Cga02 \& Cga03 & 5.815778 & 4 & 0.444140 \\
Cga01 \& Cga05 & 0.486463 & 4 & 0.974805 \\
Cga02 \& Cga05 & 2.972427 & 6 & 0.812299 \\
Cga03 \& Cga05 & 1.707876 & 6 & 0.944512 \\
Cga01 \& Cga06 & 1.059439 & 4 & 0.900653 \\
Cga02 \& Cga06 & 13.497239 & 6 & 0.035785 \\
Cga03 \& Cga06 & 2.457263 & 6 & 0.873220 \\
Cga05 \& Cga06 & 3.010361 & 6 & 0.807545 \\
Cga01 \& Cga09 & 0.000000 & 4 & 1.000000 \\
Cga02 \& Cga09 & 3.051297 & 4 & 0.549278 \\
Cga03 \& Cga09 & 1.275690 & 4 & 0.865486 \\
Cga05 \& Cga09 & 5.781304 & 4 & 0.216087 \\
Cga06 \& Cga09 & 0.933522 & 4 & 0.919703 \\
\hline
\end{tabular}

that in line with the present result came from Shikano and Taniguchi (2002) who worked with guppy, Poecilia reticulata, of different genetic background to examine the effect of genetic diversity on salinity tolerance. They found that at individual level salinity tolerance did not correlate with the multilocus heterozygosity or with mean $\mathrm{d} 2$, while at population level salinity tolerant was positively correlated with the mean heterozygosity. The results from group-level analyses obtained from the current study, despite provide strong signals of HDFC need to be treated carefully due to limited sample size used to generate the pic- ture. Hence, it could only be considered as prospective preliminary information and should be used with a high caution.

\section{Possible Causes of GDFC and Practical Impli- cations for Breeding Program}

Results of present study, as previously described, show that the relationships exist, and it is of interest to explore based on available data, the mechanisms underlying the emerging phenomena. Specifically, we examine the phenomena under three major GDFC hypotheses: direct-effect over dominance, lo- 
cal-associative over dominance, and general-associative over dominance.

The direct-effect over dominance hypothesis views that GDFC occurs due to direct effect of microsatellite loci to the fitness traits. However, this hypothesis is less likely to hold due to the widely accepted idea that microsatellite loci are selectively neutral marker (O'Malley et al., 2013), meaning that there is no direct effect of the loci to any fitness traits. Based on this argument, direct effect over dominance hypothesis could be ruled out (Bierne et $a l ., 2000$ ), and leaving associative over dominance hypothesis as possible underlying mechanism. Under associative over dominance hypotheses, fitness loci could be rest in either particular chromosome which is called local effect, or they are distributed in genome-wide known as general effect. Indicators that could be assessed to differentiate between the two hypotheses are the pattern of inbreeding reflected in heterozygote deficit (or homozygote excess) and linkage disequilibrium. Under local effect hypothesis, the heterozygote deficit occurs limited to particular chromosomes, while under general effect hypothesis, heterozygote deficit is distributed in the whole genome (David, 1998). With respect to linkage disequilibrium, local effect hypothesis would be reflected in the presence of statistical significance of several pairs of loci. In the present study, the data support both local and general effect hypotheses.

Support for local effect hypothesis came from single-locus heterozygosity (Table 4) and genotype disequilibrium (Table 5) analyses. The fact that only two loci ( $\mathrm{CgaO3}$ and $\mathrm{Cga06}$ ) that are positively correlated, and supported by disequilibrium state of those loci pairs in linkage analysis, provided supports for that hypothesis. However, that hypothesis appeared to be not the only explanation. General effect hypothesis seemed also appropriate to explain the mechanism underlying the observed GDFC, as the heterozygote deficit occurred within all loci. Assuming the loci being used are representative of the genome, it is plausible to conclude that genome-wide homozygosity as result of inbreeding as mechanism responsible for the observed GDFC in the base population of African catfish breeding program. This explanation is reasonable given the fact that population understudy are offspring of individual fish which were artificially bred in captivity. It is right that this base population are a composite population consisting of reciprocal crossing of 4 strains, which in theory inbreeding could be minimized. However, limited number of broodstock used in spawning did not allow to completely prevent inbreeding from happening. Furthermore, pooling of male gametes during artificial spawning carried out in this study, might result in differential reproductive success which lead to decreased effective breeding number and increased population's inbreeding rate.

The phenomena observed in this study where local and general effects appeared to be involved in generating the existence of GDFC were resemble to those obtained by Heath et al. (2002) who worked with chinook salmon. They found that while majority of relationships were found to be nonsignificant, one microsatellite locus, namely 0my27, was significantly correlated with reproductive fitness. Based on those findings they concluded that both local and general effects support for the existence of GDFC in chinook salmon. Independent of the mechanisms underlying GDFC, one thing that is obvious in this study is that positive correlation existed between genetic diversity and growth related traits in the base population of African catfish breeding program. Eventually, for practical purposes, it is important to see what these findings may imply for aquaculturists and breeders.

For aquaculture practitioners and breeders it is of important to have fish population having good fitness in either productive or reproductive traits. This study provides information that individuals or groups with higher genetic diversity as expressed in various indicators, proved to have higher growth related traits. For breeders, it is a clear message that maintaining a high level of genetic diversity is crucial. This finding provides support for a generally accepted proposition to maintain a high level of genetic diversity, particularly heterozygosity in a breeding population.

\section{CONCLUSIONS}

There was positive correlation between various measures of microsatellite genetic diversity and growth related traits in the base population of African catfish breeding program. The signal of correlation was weakly detected at individual level, while stronger signals were detected at group level. The $\mathrm{Cga03}$ and $\mathrm{Cga06}$ appeared to be the most contributed loci to the presence of GDFC in African catfish and deserve further exploration to take benefit for breeding program. Associative over dominance, both local effect and general effect hypotheses, were equally possible in explaining the phenomena of GDFC.

\section{ACKNOWLEDGEMENTS}

This study was a part of a broader project on genetic improvement in African catfish which was funded by research fund of Ministry of Marine Affairs and Fisheries of Fiscal year 2013. Authors would like to thank technical staffs who have made the study was successfully completed. 


\section{REFERENCES}

Appleyard, S.A., Renwick, J.M., \& Mather, P.B. (2001). Individual heterozygosity levels and relative growth performance in Oreochromis niloticus (L.) cultured under Fijian conditions. Aquaculture Research, 32, 287-296.

Bierne, N., Beuzart, I., Vonau, V., Bonhomme, F., \& Bedier, E. (2000). Microsatellite-associated heterosis in hatchery-propagated stocks of the shrimp Penaeus stylirostris. Aquaculture, 184, 203219.

Chapman, J.R., Nakagawa, S., Coltman, D.W., Slate, J., \& Sheldon, B.C. (2009). A quantitative review of heterozygosity-fitness correlations in animal populations. Molecular Ecology, 18, 2746-2765.

Coulson, T.N., Pemberton, J.M., Albon, S.D., Beaumont, M., Marshall, T.C., Slate, J., Guinness, F.E., \& Clutton-Brock, T.H. (1998). Microsatellites reveal heterosis in red deer. Proceedings of the Royal Society of London, 265, 489-495.

Da Silva, A., Luikart, G., Yoccoz, N.G., Cohas, A., \& Allaine, D. (2006). Genetic diversity-fitness correlation revealed by microsatellite analyses in European alpine marmots, Marmota marmota. Conservation Genetics, 7, 371-382.

David, P. (1998). Heterozygosity-fitness correlations: New perspectives on old problems. Heredity, 80 , 531-537.

David, P., Delay, B., \& Jarne, P. (1997). Heterozygosity and growth in the marine bivalve Spisula ovalis: testing alternative hypotheses. Genetical Research, 70, 215-223.

Del Rio-Portilla, M.A., \& Beaumont, A.R. (2000). Larval growth, juvenile size and heterozygosity in laboratory reared mussels, Mytilus edulis. Journal of Experimental Marine Biology and Ecology, 254, 117.

Diehl, W.J., \& Biesiot, P.M. (1994). Relationships between multilocus heterozygosity and morphometric indices in a population of the deep-sea red crab, Chaceon quinquedens (Smith). Journal of Experimental Marine Biology and Ecology, 182, 237250.

Frankham, R., Ballou, J.D., \& Briscoe, D.A. (2002). Introduction to conservation genetics Cambridge University Press, Cambridge.

Galbusera, P., Volckaert, F.A., Hellemans, B., \& Ollevier, F. (1996). Isolation and characterization of microsatellite markers in the African catfish, Clarias gariepinus (Burchell, 1822). Molecular Ecology, 5, 703-705.

Goudet, J. (2001). FSTAT, a program to estimate and test gene diversities and fixation indices (version 2.9.3). Available from http://www.unil.ch/izea/ softwares/fstat.html.

Hansson, B. (2010). The use (or misuse) of microsatellite allelic distances in the context of inbreeding and conservation genetics. Molecular Ecology, 19, 1082-1090.

Hansson, B., \& Westerberg, L. (2002). On the correlation between heterozygosity and fitness in natural populations. Molecular Ecology, 11, 2467-2474.

Heath, D.D., Bryden, C.A., Shrimpton, J.M., Iwama, G.K., Kelly, J., \& Heath, J.W. (2002). Relationships between heterozygosity, allelic distance $(\mathrm{d} 2)$, and reproductive traits in chinook salmon, Oncorhynchus tshawytscha. Canadian Journal of Fisheries and Aquatic Sciences, 59, 77-84.

Imron, Sunandar, D., \& Tahapari, E. (2011). Microsatellite genetic variation in cultured population of African catfish, Clarias gariepinus, in Indonesia. Indonesian Aquaculture Journal, 6, 1-10.

Kittiwattanawong, K. (2001). Correlation of multilocus heterozygosity to growth rate, oxygen consumption, and morphological characteristics in Cerastoderma edule (Bivalvia: Cardiidae). Phuket Marine Biological Center Special Publication, 25, 323-341.

Kretzmann, M., Mentzer, L., DiGiovanni Jr, R., Leslie, M.S., \& Amato, G. (2006). Microsatellite diversity and fitness in stranded juvenile harp seals, Phoca groenlandica. Journal of Heredity, 97, 555-560.

Liu, G.Q., Jiang, X.P., Wang, J.Y., \& Wang, Z.Y. (2006). Correlations between heterozygosity at microsatellite loci, mean $\mathrm{d} 2$ and body weight in a Chinese native chicken. Asian-Australian Journal of Animal Sciences, 19, 1671-1677.

Mitton, J.B., \& Pierce, B.A. (1980). The distribution of individual heterozygosity in natural populations. Genetics, 95, 1043-1054.

O’Malley, K.G., Jacobson, D.P., Kurth, R., Dill, A.J., \& Banks, M.A. (2013). Adaptive genetic markers discriminate migratory runs of Chinook salmon, Oncorhynchus tshawytscha, amid continued gene flow. Evolutionary Applications, 6, 1184-1194.

Pierce, B.A., \& Mitton, J.B. (1982). Allozyme heterozygosity and growth in the tiger salamander, Ambystoma tigrinum. Journal of Heredity, 73, 250-253.

Primmer, C.R., \& Tiira, K. (2009). Genetic diversity and fitness-related traits in endangered salmonids, In G. Bertorelle, et al., eds. Population Genetics for Animal Conservation. Cambridge University Press, New York.

Raymond, M., \& Rousset, F. (1995). GENEPOP (version 1.2) population genetics software for exact test and ecumenism. Journal of Heredity, 86, 248249.

Reed, D.H., \& Frankham, R. (2001). How closely correlated are molecular and quantitative measures 
of genetic variation? a meta analysis. Evolution, 55, 1095-1103.

Reed, D.H., \& Frankham, R. (2003). Correlation between fitness and genetic diversity. Conservation Biology, 17, 230-237.

Rolan-Alvarez, E., Zapata, C., \& Alvarez, G. (1995). Multilocus heterozygosity and sexual selection in a natural population of the marine snail, Littorina mariae, (Gastropoda: Prosobranchia). Heredity, 75, 17-25.

Saavedra, C., \& Guerra, A. (1996). Allozyme heterozygosity, founder effect and fitness traits in a cultivated population of the European oyster, Ostrea edulis. Aquaculture, 139, 203-224.

Schneider, S., Roessli, D., \& Excoffier, L. (2000). Arlequin; A software for population genetic analysis data, 2.000 ed. Genetic and Biometry Laboratory, University of Geneva, Switzerland, 111 pp.
Shikano, T., \& Taniguchi, N. (2002). Relationships between genetic variation measured by microsatellite DNA markers and a fitness-related trait in the guppy, Poecilia reticulata. Aquaculture, 209, 7790.

Slate, J., David, P., Dodds, K.G., Veenvliet, B.A., Glass, B.C., Broad, T.E., \& McEwan, J.C. (2004). Understanding the relationship between the inbreeding coefficient and multilocus heterozygosity: Theoretical expectations and empirical data. Heredity, 93, 255-265.

Wright, J.M., \& Bentzen, P. (1994). Microsatellites: genetic markers for the future. Reviews in Fish Biology and Fisheries, 4, 384-388.

Zouros, E., Singh, S.M., \& Miles, H.E. (1980). Growth rate in oysters: an overdominant phenotype and its possible explanations. Evolution, p. 856-867. 